\title{
On the Incomplete Architecture
} of Human Ontogeny

\section{Selection, Optimization, and Compensation as Foundation}

\section{of Developmental Theory}

\author{
Paul B. Baltes \\ Max Planck Institute for Human Development and Education, Berlin
}

Drawing on both evolutionary and ontogenetic perspectives, the basic biological-genetic and social-cultural architecture of human development is outlined. Three principles are involved. First, evolutionary selection pressure predicts a negative age correlation, and, therefore, genome-based plasticity and biological potential decrease with age. Second, for growth aspects of human development to extend further into the life span, culturebased resources are required at ever-increasing levels. Third, because of age-related losses in biological plasticity, the efficiency of culture is reduced as life span development unfolds. Joint application of these principles suggests that the life span architecture becomes more and more incomplete with age. Degree of completeness can be defined as the ratio between gains and losses in functioning. Two examples illustrate the implications of the life span architecture proposed. The first is a general theory of development involving the orchestration of 3 component processes: selection, optimization, and compensation. The second considers the task of completing the life course in the sense of achieving a positive balance between gains and losses for all age levels. This goal is increasingly more difficult to attain as human development is extended into advanced old age.

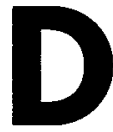

uring the last decade, we have witnessed a vigorous effort to strengthen the link between evolutionary and ontogenetic perspectives in the study of human behavior. In this spirit, the purpose of this article is to offer a general framework of the biological and cultural architecture of human development across the life span. With this approach, which considers both evolutionary and ontogenetic arguments, I hope to identify the foundational structure that any general theory of human development must have.

Many of the arguments presented owe their line of reasoning to theoretical propositions associated with life span developmental psychology (P. B. Baltes, 1979, 1987; P. B. Baltes, Lindenberger, \& Staudinger, in press; Elder, in press; Featherman, 1983; Labouvie-Vief, 1982). The arguments are also consistent with more recent theoretical efforts claiming that ontogenesis is inherently a system of adaptive change involving as foundational elements the orchestration of three subprocesses: selection, optimization, and compensation (M. M. Baltes \& Carstensen, 1996; P. B. Baltes \& Baltes, 1980, 1990; Heckhausen \& Schulz, 1995; Marsiske, Lang, Baltes, \& Baltes, 1995; Nesselroade \& Jones, 1991).

Especially relevant for the present article is the notion that since the classical work of Tetens (1777), life span scholars proceeded in their theoretical efforts from the basic assumption that human development essentially is incomplete. In this article, I contend that this incompleteness of what I call the biological and cultural architecture of life span development is less promising than an unfinished Schubert symphony. The situation is more like an ill-designed building in which inherent vulnerabil-

Editor's note. Cheryl B. Travis served as action editor for this article. Articles based on APA award addresses are given special consideration in the American Psychologist's editorial selection process.

A version of this article was originally presented as part of an Award for Distinguished Contributions to the International Advancement of Psychology address at the 104th Annual Convention of the American Psychological Association, Toronto, Ontario, Canada, August 1996.

Author's note. I gratefully acknowledge the many valuable discussions with and contributions by Margret Baltes, Laura Carstensen, Caleb Finch, Alexandra Freund, Ulman Lindenberger, Michael Marsiske, John Nesselroade, Jacqui Smith, and Ursula Staudinger. In addition, I thank the MacArthur Research Network on Successful Midlife Development (O. G. Brim, director) for their generous intellectual and financial support.

Correspondence concerning this article should be addressed to Paul B. Baltes, Lentzeallee 94, Max Planck Institute for Human Development and Education, 14195 Berlin, Germany. Electronic mail may be sent via Internet to sekbaltes@mpib-berlin.mpg.de. 
ities, as old age is reached, become more and more manifest.

The incompleteness of life span human development results primarily from two conditions. Incompleteness results first from the fact that biological and cultural coevolution (Durham, 1991) has not come to a standstill but is an ongoing process. Second, and most important, incompleteness results from the fact that the biological and cultural architecture of human ontogeny is relatively undeveloped for the second part of the life span (P. B. Baltes, 1991; P. B. Baltes \& Graf, 1996). Neither biological nor cultural evolution has had sufficient opportunity to evolve a full and optimizing scaffolding (architecture) for the later phases of life. A seeming paradox exists: Historically speaking, old age is young.

To explore this incompleteness argument and its implications for the future potentials of human development, life span researchers have focused their work on searching for methods to study age-related changes in plasticity (potential) and for conceptualizations that permit the definition of successful or effective human development. One general approach to this topic has been to define successful development as the relative maximization of gains and the minimization of losses (M. M. Baltes \& Carstensen, 1996; P. B. Baltes, 1987; P. B. Baltes \& Baltes, 1990; Brandtstädter \& Wentura, 1995; Marsiske et al., 1995).

Such a gain-loss approach also permits the definition of degrees of completeness or incompleteness of the life span. Using the ratio between achieved gains and losses as a criterion for evaluation, the life span architecture would be the more complete, the more, in all age periods of the life course, individuals were to show relatively more gains than losses in functioning. Instead of gains and losses, it would be possible also to use desirable and undesirable states as criteria. Currently, as described below in more detail, this pattern of relative completeness does not exist for all phases of life. Beginning in late adulthood and certainly in old age, losses outnumber gains, and with age the balance becomes less positive (P. B. Baltes, 1987).

The determination of what is a gain or a loss in ontogenetic change is a topic of theoretical as well as empirical inquiry (see also M. M. Baltes \& Carstensen, 1996; Brandtstädter, 1984; Hobfoll, 1989; Kahneman \& Tversky, 1984; Labouvie-Vief, 1982; Schulz \& Heckhausen, 1996). Suffice it here to mention that the nature of what is considered a gain or a loss can change with age; involves objective in addition to subjective criteria; and is conditioned by theoretical predilection, standards of comparison, cultural and historical context, as well as by criteria of functional fitness or adaptivity.

\section{Architecture of Life Span Development: The Frame Resulfing From Biological and Cultural Coevolution}

What is the role of cultural and biological factors in ontogenesis across the life span-how do they interact and condition each other, for instance, in the sense of biocultural coevolution (Durham, 1991)? What is the zone of development, the norm of reaction, and the modifiability or plasticity (P. B. Baltes, 1987; P. B. Baltes \& Schaie, 1976; Lerner, 1984, 1986; Magnusson, 1996) that one can expect to operate during ontogenesis? On the basis of genetic- and evolution-based factors and availability of cultural structures, only certain pathways can be implemented during ontogenesis, and some of these are more likely to be realized than others. Despite the sizable plasticity of Homo sapiens and the dynamic quality of such conceptions as norms of reaction, zone of development, or plasticity, not everything is possible in ontogenetic development. Although open, development inherently is also limited.

Figure 1 illustrates the main lines of argument that I submit as being the three foundational (constraining) principles of the life span architecture of human ontogeny (P. B. Baltes, 1994; P. B. Baltes et al., in press). Note first that the specific form (level, shape) of the three life span functions depicted in Figure 1 is not critical. What is critical are the overall direction and reciprocal interactions between the functions displayed.

\section{Evolutionary Selection Benefits Decrease With Age}

The first foundational principle of my view of the life span architecture states that the benefits resulting from evolutionary selection evince a negative age correlation (Finch, 1990, 1996; Finch \& Rose, 1995; Martin, Austad, \& Johnson, 1996; Osiewacz, 1995; Rose, 1991; Yates \& Benton, 1995). As a consequence, the human genome in older ages is predicted to contain an increasingly larger number of deleterious genes and dysfunctional gene expressions than in younger ages.

Why did whatever happened later in the life span benefit less from the optimizing power of evolutionary selection pressure? The primary reason is that reproductive fitness, the essential component of natural selection, involved the transmission of genes in the context of fertility and parenting behavior, events and processes that typi-

\section{Figure 1}

Schematic Representation of Three Principles Governing the Dynamics Between Biology and Culture Across the Life Span

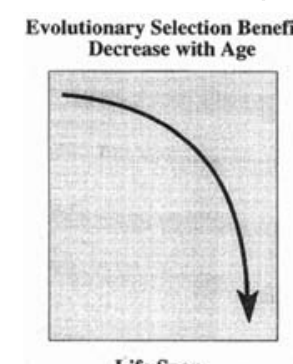

Life Span

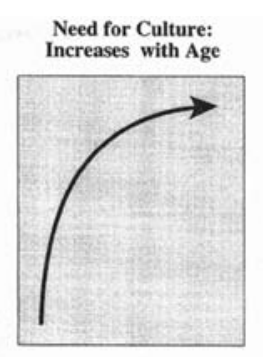

Life Span

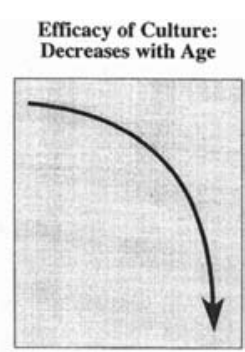

Life Span 
cally extend from conception to earlier adulthood. As a consequence, over evolutionary history, selection operated more strongly on the first half of life. Moreover, given the much shorter life span in early human evolution, selection pressure could not operate as frequently to begin with when it came to the second half of life. Most individuals died before possible negative genetic attributes were activated or their possible negative consequences could become manifest.

One concrete illustration of this aging-based weakening of evolutionary selection benefits is the existence of late-life illnesses such as Alzheimer's dementia (for other examples, see Martin et al., 1996). This disease typically does not become manifest until age 70 . After age 70 , however, dementia of the Alzheimer's type increases markedly in prevalence (for specific data, see below). Alzheimer's dementia is at least in part a late-life disease because reproductive fitness-based evolutionary pressure was unable to select against it. Geneticists (e.g., Martin et al., 1996) call such a situation selection neutrality.

There are other aspects of a biology of aging that, together and separately, imply an age-associated loss in biological potential, and whose operation amplifies the evolutionary neglect of old age (e.g., Finch, 1996; Martin et al., 1996). Many of these age-related biological losses are associated with the mechanisms of ontogenesis itself. Among the prevalent explanations for biological aging losses are wear-and-tear theories, entropy-based conceptions, as well as interpretations related to the sources of age-accumulated increases in mutations.

These various considerations about the role of genetic and biological factors converge into an unequivocal conclusion regarding the dynamics of biological factors in life span development. Where evolutionary selection and the ontogenetic biology of aging are concerned, the life span of humans displays an unfinished architecture, and in this instance, and certainly after physical maturity, the consequences of this incompleteness are essentially negative or dysfunctional. With age, the genetic material, associated genetic mechanisms, and genetic expressions become less effective and less able to generate or maintain high levels of functioning. Evolution and biology are not good friends of old age.

\section{Age-Relatod Increase in Need (Demand) for Culture}

The second cornerstone of a life span architecture of human ontogenesis states that there is an age-related increase in the need or demand for culture (middle part of Figure 1). Culture in this context refers to the entirety of psychological, social, material, and symbolic (knowledge-based) resources that humans have generated over the millenia, and which as they are transmitted across generations, make human development possible as we know it today (Boesch, 1991; Cole, 1996; D'Andrade, 1995; Durham, 1991; Shweder, 1991). For human ontogenesis to achieve increasingly higher levels of functioning, for instance, to live longer or to be able to read and write, there had to be a conjoint evolutionary increase in the content and dissemination of culture. And the further we expect human ontogenesis to extend itself into adult life and old age, the more it will be necessary for particular cultural factors and resources to emerge and operate to make this possible.

To appreciate the power of the evolution of such culture-based resources, consider what happened to average life expectancy in industrialized countries during the 20 th century. It was not the genetic make-up of the population that evinced marked changes during this time. On the contrary, it was economic and technological innovations that produced significant additions to average life expectancy, from an average of about 45 years in 1900 to about 75 years in 1995. Similarly, the dramatic increase in literacy rates over the last centuries in industrialized nations was not the result of a change in the genome (that requisite evolution took place at a much earlier time many millenia ago; e.g., Klix, 1993) but, above all, a change in environmental contexts, cultural resources, and strategies of education.

There is a second argument for the proposition that, with age, the need for the supportive and enriching role of culture increases. The demand for culture also increases because, as individuals reach old age, their biological potentials decline (left part of Figure 1). The older in age individuals are, the more they are in need of culturebased compensations (e.g., material, technical, social, economic, psychological) to generate and maintain high levels of functioning. This view of "culture as compensation" is a major tenet of many evolutionary theories in cultural anthropology (P. B. Baltes, 1991; Brandtstädter, in press; Dixon \& Bäckman, 1995; Durham, 1991; Marsiske et al., 1995). Consider the evolution of clothing in its many variations as an example. At the evolutionary base is a biological lack. Humans wear cloth in part because of a thermoregulation deficit.

\section{Age-Related Decrease in Efficiency of Culture}

The right panel of Figure 1 illustrates the third cornerstone of the overall architecture of the life course. This foundational principle states that there is an age-related loss in the effectiveness or efficiency of cultural factors and resources. With age, and conditioned primarily by the negative biological trajectory of the life course, the relative power (effectiveness) of psychological, social, material, and cultural interventions wanes. In summary, although there continues to be plasticity in the second half of life - and its extent may even be larger than typically believed (M. M. Baltes \& Carstensen, 1996; P. B. Baltes, 1987; Lerner, 1984; Willis, 1990) - the scope of plasticity of the human organism declines with age.

Take cognitive learning in old age as an example (P. B. Baltes, 1993; Birren \& Schaie, 1996; Craik \& Salthouse, 1992; Lindenberger \& Baltes, 1995; Salthouse, 1991). The older the adult is, the more time, practice, and cognitive support it takes to attain the same learning gains. Moreover, when it comes to high levels of performance, older adults may never be able to reach the same levels of functioning as younger adults even 
after extensive training (P. B. Baltes \& Kliegl, 1992; Ericsson \& Smith, 1991; Kliegl, Mayr, \& Krampe, 1994; Kliegl, Smith, \& Baltes, 1989). Similar conclusions apply to life span changes in neuronal plasticity (Magnusson, 1996). Neuronal plasticity continues to exist across the life span, but with age it is reduced in scope and efficiency.

This third principle of an age-related reduction in cultural efficiency is likely to raise objections in social science circles. Two reasons are central. A first objection is the notion that the specifics of cultural systems, namely their symbolic form, may follow different mechanisms of efficiency. For instance, the life span developmental entropy costs of symbolic systems may be more favorable than those observed for basic biological processes (P. B. Baltes \& Graf, 1996). Second, some social scientists argue that the concept of efficiency contains assumptions about human functioning that are inherently opposed to phenomena such as meaning of life, a sense of religion, or an understanding of one's finitude (P. B. Baltes et al., in press; Dittmann-Kohli, 1995; Rosenmayr, 1990). These are serious lines of argument. However, I submit that such perspectives, important and critical as they are for an understanding of human development, do not alter the general direction of the life span function outlined. In other words, the primary impact of symbolic systems and related meaning systems is on level, rate, and the life span extension of cultural efficiency, not on its ontogenetic directional course.

I submit that the three propositions and trajectories outlined in Figure 1 form a robust architecture of the life span dynamics between biology and culture. This architecture, including its growing incompleteness as the life course unfolds, represents the most general frame within which developmental theory is embedded. Whatever the specific content and form of a given psychological theory of human ontogeny, they need to be consistent with this architectural frame. For instance, any theory of life span development that were to posit "general" positive advances across broad domains of functioning in later adulthood can be judged to be false. Similarly false would be the view that development at any age could consist of pure gain. In the past, as argued for instance by Hetherington and Baltes (1988) and Labouvie-Vief (1982), such a pure-gain view of development was often held by cognitive child developmentalists.

Why is a pure-gain view of ontogenesis false? As is true for evolution, ontogenetic adaptivity and ontogenetic attainments are always local, that is, context, space and time (age) bound. In addition, development always involves selection and, therefore, a trade-off between alternative pathways and success-failure constellations. This recognition has led life span theorists such as Jochen Brandtstädter, Gisela Labouvie-Vief, and myself to reject any conception of development that is unilinear and based solely on the notion of growth as a unidimensional advance in quantity and quality of functioning. On the contrary, multicausality, multidimensionality, multidirectionality, and multifunctionality reign supreme in ontogenesis at all stages of the life course (M. M. Baltes, 1996; P. B. Baltes, 1987; P. B. Baltes et al., in press; Brandtstädter, in press; Labouvie-Vief, 1982; Marsiske et al., 1995; Schulz \& Heckhausen, 1996; Uttal \& Perlmutter, 1989).

The changing life span dynamics in the ratio of gains and losses are also evident at the level of subjective beliefs about the overall developmental trajectory of gains and losses across the life span (Heckhausen, Dixon, \& Baltes, 1989). For instance, when asked about the typical adult developmental trajectory of a large number of attributes (such as intelligent, strong, anxious, sick, etc.), persons report a script that involves a changing ratio of gains and losses toward an increasingly less desirable balance (see left part of Figure 2). With increasing age, more and more of the expected changes involve losses rather than gains, although there continue to be some expectations of gains in old age, such as an increase in dignity and wisdom. And with this changing ratio between gains and losses, there is a corollary change in the expected proportion of success and failure experiences (Schulz \& Heckhausen, 1996).

This life span script about gains and losses has consequences for the subjective experience of life span development. Thus, when persons of different ages are asked about what age they would like to be, they report an increasing negative discrepancy between their actual age and their desired age (Smith \& Baltes, 1996). Seventyyear-olds, for instance, would like to be on average about 10 years younger. For 90 -year-olds, the discrepancy is increased to about 25 years. These findings of an agerelated increase in the discrepancy between actual age and desired age lend support to the reality of a growing disjuncture between body and mind-between what is desirable and what is possible. These findings also illustrate that the beliefs that individuals hold about the life course reflect the biological and cultural incompleteness of the life span and the resulting age-related increase in less desirable outcomes.

\section{Life Span Changes in the Allocation of Resources to Functions of Development}

In the following section, I pursue a strategy where the implications of this overall architectural landscape of human development are examined at levels of analysis that step-by-step approximate the kind of questions that developmental psychologists study. A first step in this direction, and as illustrated in the right part of Figure 2, involves consideration of three general functions or outcomes of development: (a) the function of growth; (b) the function of maintenance, including recovery (resilience); and (c) the function of regulation of loss. These three functions and their associated outcomes represent the systemic whole of individual development (see also Staudinger, Marsiske, \& Baltes, 1995).

With the adaptive function of growth, I refer to behaviors involved in reaching higher levels of functioning or adaptive capacity. Under the heading of maintenance and recovery (resilience), I classify behaviors involved in maintaining levels of functioning in the face of a new 


\section{Figure 2}

Life Span Script of Allocation of Resources to Functions of Development
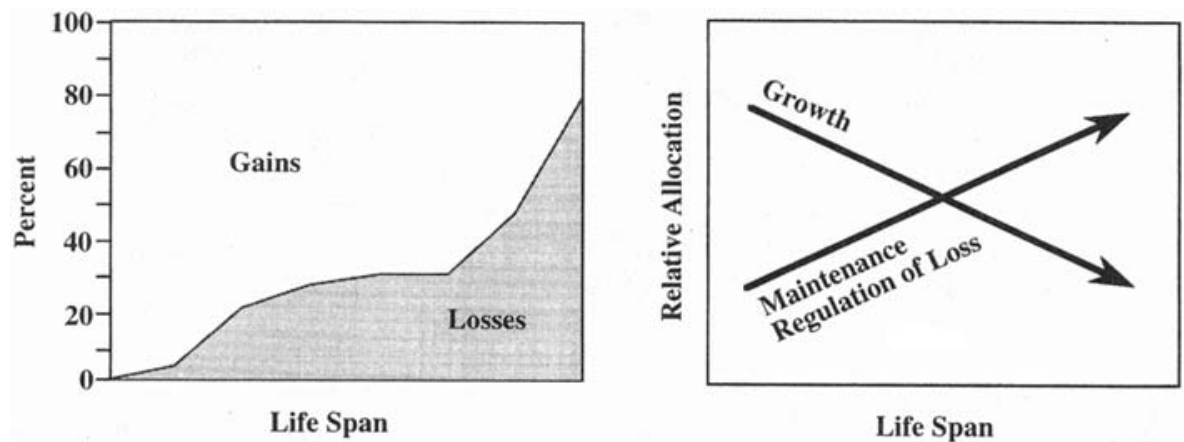

Note. The left part shows subjective expectations about desirable (gains) and undesirable (losses) changes across adulthood on the basis of Heckhausen, Dixon, and Baltes (1989). The right side illustrates life span changes in the allocation of resources into three functions of development: growth, maintenance (resilience), and regulation of loss (Staudinger, Marsiske, \& Baltes, 1995).

contextual challenge or a loss in potential. Finally, regarding regulation of loss or management, I mean behaviors that organize functioning at lower levels when maintenance or recovery (resilience) is no longer possible.

Because of the architecture outlined above, my colleagues and $I$ argue that there is a systematic life span shift in the relative allocation of resources to these three functions (P. B. Baltes, 1994; P. B. Baltes et al., in press; Marsiske et al., 1995; Staudinger et al., 1995). In childhood, the primary allocation is directed toward growth; during adulthood, the predominant allocation is toward maintenance and recovery (resilience). In old age, more and more resources are directed toward regulation or management of loss. Such a characterization of the life span, of course, is an oversimplification, as individual, functional (domain), contextual, and historical differences need to be taken into account. The life span script is about relative probability and prevalence. Note in this context that the reallocation of resources toward maintenance of functioning and regulation of loss is facilitated by the tendency of individuals to prefer avoidance of loss over enhancement of gains (Hobfoll, 1989; Kahneman \& Tversky, 1984).

The life span trajectories regarding investment of resources into growth, resilience, and regulation of loss also have implications for the dynamics involved in the systemic and integrative coordination of these three functions. A first telling research example is the strong interest of adult development researchers in topics such as selection of goals (Cantor \& Fleeson, 1994) but especially compensation (Bäckman \& Dixon, 1992; P. B. Baltes \& Baltes, 1990; Dixon \& Bäckman, 1995). And when considering compensation, theoretical considerations include the seemingly counterintuitive view that deficits can breed advances through innovative efforts (P. B. Baltes, 1987, 1991; Burghardt, 1984; Uttal \& Perlmutter, 1989). Such a view, incidentally, is consistent with evolutionary theory, where it is widely held that during evolution, increases in adaptive capacity were enhanced by conditions of stress and challenge (anagenesis).

Another telling example of the dynamics among the functions of growth, resilience, and regulation of loss is the life span study of the interplay between autonomy and dependency in children and older adults (M. M. Baltes, 1996). Whereas the primary focus of the first half of life is the maximization of autonomy, in old age, the productive and creative use of dependent behavior becomes critical. According to Margret Baltes, for older adults to maintain autonomy in select domains of functioning, the effective exercise and use of dependent behavior is a compensatory must. By invoking dependency and support, resources are freed up for use in other domains "selected" for personal efficacy and growth. Similar perspectives, of course, can be applied to functioning in childhood, such as the nature of child care or motor development (Hetherington \& Baltes, 1988; LabouvieVief, 1982; Thelen \& Smith, 1994).

\section{Selective Optimization With Compensation: An Example of a General (Systemic) Theory of Life Span Development}

In this section, I add another level of analysis and apply the basic life span architectural frame to the formulation of a general model of development. For this purpose, I characterize a metatheory of development, selective optimization with compensation (SOC), which, together with several colleagues, Margret Baltes and I have developed over the last decade (M. M. Baltes \& Carstensen, 1996; P. B. Baltes, 1987; P. B. Baltes \& Baltes, 1980, 1990; P. B. Baltes, Dittmann-Kohli, \& Dixon, 1984; Carstensen, Hanson, \& Freund, 1995; Marsiske et al., 1995).

In our work on SOC, the original intellectual motivation was the search for a general process of systemic functioning that would serve as an effective strategy for 
dealing with the life span architecture described above. We began by using the field of aging as a testing ground (P. B. Baltes \& Baltes, 1990). The following everyday example was one of our early illustrations of SOC. When the concert pianist Arthur Rubinstein, as an 80-year-old, was asked in a television interview how he managed to maintain such a high level of expert piano playing, he hinted at the coordination of three strategies. First, $\mathrm{Ru}$ binstein said that he played fewer pieces (selection); second, he indicated that he now practiced these pieces more often (optimization); and third, he suggested that to counteract his loss in mechanical speed, he now used a kind of impression management, such as introducing slower play before fast segments, so to make the latter appear faster (compensation). Using such a SOC-related strategy and paraphrasing a quotation from Hesiod, "Half can be more than the whole."

Meanwhile, my colleagues and I have enlarged this view and emphasize that the orchestration of selection, optimization, and compensation is not unique to human aging but inherent in any developmental process (P. B. Baltes \& Graf, 1996; P. B. Baltes et al., in press; Marsiske et al., 1995; see also chapter by Edelman \& Tononi, 1996). Beginning with birth, if not at conception, humans select, optimize, and compensate. In this sense, we view SOC as a general frame for developmental theory. We further argue that this general theoretical approach is consistent with the life span architecture outlined above.

The essential nature of selection in ontogenesis follows from several arguments. One is that development always has a specific set of targets (goals) of functioning. Second, development always proceeds within the condition of a limited capacity, including constraints in time and resources. Moreover, selection is conditioned by the very fact that organisms possess behavioral dispositions (e.g., sensory modalities, motor repertoires, cognitive mechanics) that during evolution were selected from a pool of potentialities. Furthermore, in reflection of the left part of Figure 1, selection is conditioned by age-related changes in plasticity and associated losses in potential. Age-associated losses in biological potential or plasticity increase the pressure for selection.

Because most examples in this article have their origin in the field of adult development and aging, the following illustrations are taken from the field of infant and child development. The biologist Waddington (1975; see also Edelman, 1987) was perhaps the first powerful spokesperson for the notion of development as selective "canalization." A specific example of selection in early life is the acquisition of language (Levelt, 1989). Although infants around the world seem to possess the same basic dispositons for the recognition and production of language, their ontogenetic development is shaped in specific (selected) directions of sound recognition and sound production by the realization (acquisition) of a particular language. Thus, the acquisition of language involves from the ontogenetic beginning selection phenomena, with associated gains and losses in performance potential. Another concrete illustration of selection is the acquisition of cognitive stages in child development. Take Piagetian theory as an example. It has become increasingly recognized that the ontogenetic movement toward a "final" stage of formal logical reasoning is the effect of a culturebased selection process. Another approach closely related to the notion of development as selection is the work of Siegler (1994) who treated the ontogeny of cognitive skills and strategies in children as the outcome of variability-based selection from a larger pool of potentialities.

Optimization is the hallmark of any traditional conception of development. Development is widely considered as a movement toward increased efficacy and higher levels of functioning. My colleagues and I argue that human development, as an optimizing positive change in adaptive capacity toward a set of desirable outcomes (goals), requires in concert the application of a set of behavior-enhancing factors such as cultural knowledge, physical status, goal commitment, practice, and effort. The component elements that are relevant for the task of optimization vary by domain and developmental status. And from an ontogenetic point of view, of course, the concept of optimization undergoes developmental changes in the components and mechanisms involved as well. Research on the development of expertise in children and adults is a good example (Ericsson \& Smith, 1991).

Compensation, finally, is operative whenever a given set of means is no longer available, either because of direct losses of these means (e.g., hearing loss), because of negative transfer (e.g., incompatibility between goals), or because of new limiting constraints in time and energy (e.g., the exclusive consumptive focus on the tasks of resilience and regulation of loss). Compensation, then, has multiple origins and comes in varied forms.

Researchers in the field of aging have little trouble evoking examples of compensation (M. M. Baltes \& Carstensen, 1996; P. B. Baltes et al., 1984; Dixon \& Bäckman, 1995; Schulz \& Heckhausen, 1996). This is different for researchers in the field of child development in which the prevalent view is on gain and advances in functioning. Because of our predominant concern with development as growth in childhood and with the exception of compensatory responses to pathological conditions such as deafness or blindness, we know relatively little about the functional role that compensation plays in normal child and adolescent development. A first line of thinking involves losses in means (resources), which result in the sense of "negative transfer" from advances in those means that are directly targeted for developmental enhancement. As children move toward decontextualized thinking in the formal-logical sense, for instance, their ability for play, imagery, as well as divergent modes of thinking may decline. Similarly, as adolescents opt for particular pathways of athletic development, their skills in other kinds of sports are reduced. In this instance both negative transfer and a reduced amount of practice are involved. Or consider interpersonal issues such as those associated with the emergence of autonomy during 
adolescence (M. M. Baltes \& Silverberg, 1994). As adolescents sharpen their means of autonomy, their means of relating to their parents lose in efficacy. Consideration of the sequelae of this parent-adolescent dynamic also illustrates how losses in means can represent temporary conditions for subsequent advances, such as when adolescents and their parents at later points reach a new and possibly more advanced (egalitarian) form of communication and relatedness.

These examples already illustrate that how selection, optimization, and compensation are defined differs by theoretical framework and domains of functioning. Within an action-theoretical framework (Boesch, 1991; Brandtstädter, in press), for instance, the following characterizations of the three components hold: Selection involves directionality, goals, or outcomes; optimization involves means to achieve success (desired outcomes); and compensation denotes a response to loss in means (resources) used to maintain success or desired levels of functioning (outcomes).

Table 1 illustrates the kind of category of behaviors and items my colleagues and I apply when measuring behaviors of selection, optimization, and compensation-in this case, by means of a questionnaire (P. B. Baltes, Baltes, Freund, \& Lang, 1995; Freund \& Baltes, 1996). The use of action-theoretical perspectives might suggest to some readers the conclusion that SOC is intended always to be a process with intention and rationality, but this is not so. Rather, each of these elements or components can be active or passive, internal or external, or conscious or unconscious. Moreover, during ontogenesis, the status of these components can change, for instance, from compensation to optimization (Marsiske et al., 1995).

The SOC theory is inherently a systemic and functionalist one. Its focus is on the whole and the coordination of its parts in terms of three functions (selection, optimization, and compensation). The theory is also highly general. Therefore, we label it a metatheory. Be- cause SOC does not designate the specific content and mechanisms of developmental processes and outcomes, it is applicable to a large range of variations in goals and means. One recent example is the application of SOC to the topic of control, which results in a life span theory of successful aging by means of an adaptive combination of primary and secondary control (Heckhausen \& Schulz, 1995; Schulz \& Heckhausen, 1996).

One may wonder whether the SOC theory carries a cultural bias. Is its conceptualization specific to industrialized Westernized societies? The use of the terms selection, optimization, and compensation, by themselves and because of their frequent association with economic criteria of productivity, may suggest such a possibility. Aside from the context of these terms, however, I argue that this is not the case. As a metatheory, that is, a developmental theory about developmental theories, SOC is open in regard to its phenotypic realization. In fact, I consider it the special strength of this theory, that it is at the same time relativistic and universalistic.

The relativity of SOC lies in the variations of physical, motivational, social, and intellectual resources, as well as in the criteria used to define successful development (P. B. Baltes \& Baltes, 1990). SOC is definitely context- and person-conditioned. Thus, SOC, depending on sociocultural context, individual resources, and personal preferences, can be implemented in very different ways and by different means. Take the context of Japan as an example. If in Japan, for instance, and in comparison with Western cultures, the primary focus of social development is more on family-boundedness and on social interdependence and less on individuality and individual competitiveness, as Takahashi (1990) reported, such a cultural difference can be illuminated by representing these differences in terms of the nature of selection, optimization, and compensation.

The universalism (generality) of SOC rests in the argument that any process of development is expected to involve some orchestration of selection, optimization,

\section{Table 1}

Selection, Optimization, and Compensation Embedded in an Action-Theoretical Framework (After P. B. Baltes, Baltes, Freund, \& Lang, 1995; Freund \& Baltes, 1996)

\begin{tabular}{|c|c|c|}
\hline $\begin{array}{l}\text { Selection } \\
\text { (goals/preferences) }\end{array}$ & $\begin{array}{l}\text { Optimization } \\
\text { (goal-relevant means) }\end{array}$ & $\begin{array}{c}\text { Compensation } \\
\text { (means/resources for counteracting loss/decline } \\
\text { in goal-relevant means) }\end{array}$ \\
\hline $\begin{array}{l}\text { Elective selection } \\
\text { Specification of goals } \\
\text { Goal system (hierarchy) } \\
\text { Contextualization of goals } \\
\text { Goal commitment } \\
\text { Loss-based selection } \\
\text { Focusing on most important goal(s) } \\
\text { Search for new goals } \\
\text { Reconstruction of goal hierarchy } \\
\text { Adaptation of standards }\end{array}$ & $\begin{array}{l}\text { Aftentional focus } \\
\text { Effort/energy } \\
\text { Time allocation } \\
\text { Practice of skills } \\
\text { Acquiring new skills/resources } \\
\text { Modeling successful others } \\
\text { Motivation for self-development }\end{array}$ & $\begin{array}{l}\text { Increased aftentional focus } \\
\text { Increased effort/energy } \\
\text { Increased time allocation } \\
\text { Activation of unused skills/resources } \\
\text { Acquiring new skills/resources } \\
\text { Modeling successful others who compensate } \\
\text { Use of external aids/help of others } \\
\text { Therapeutic intervention }\end{array}$ \\
\hline
\end{tabular}


and compensation and that with age, because of the basic architecture of the life course, selection and compensation become increasingly important to maintain adequate levels of functioning and permit advances in select domains of functioning (M. M. Baltes \& Carstensen, 1996; P. B. Baltes \& Baltes, 1990; Dixon \& Bäckman, 1995; Marsiske et al., 1995). One interesting and as yet uncharted challenge is to link SOC to other theories of development (Lerner, 1986). How would one reconstruct, for instance, Piagetian or Eriksonian theory in terms of selection, optimization, and compensation? In my view, such an effort would be a concrete test of the generality or metatheoretical usefulness of the SOC approach.

\section{The Sample Case of Life Span Intellectual Development}

In the opening sections, I argued that the life span architecture and SOC provide a general frame for the study and organization of any developmental phenomenon. In this section, I have chosen the example of life span intellectual development to examine the degree to which these general frameworks on development are consistent with extant psychological research on human ontogeny (P. B. Baltes, 1993; P. B. Baltes et al., 1984; P. B. Baltes et al., in press).

The life span architectural frame outlined in Figure 1 suggests different trajectories for biological and cultural processes. In line with this frame, it has become theoretically useful to distinguish between two main categories of intellectual functioning: the fluid mechanics and the crystallized pragmatics. Although the fluidcrystallized distinction dates back to the early work of Hebb (1949), Cattell (1971), and Horn (1970), embedding this distinction into the present line of theoretical argument makes these theories appear in a new and enriched framework, as Figure 3 illustrates.

Using a computer metaphor, one can conceptualize the fluid cognitive mechanics as reflecting the neurophysiological "hardware" (Barkow, Cosmides, \& Tooby, 1992) or cognitive primitives (Salthouse, 1991) of the

\section{Figure 3}

The Dual-Process Model of Life Span Intellectual Development

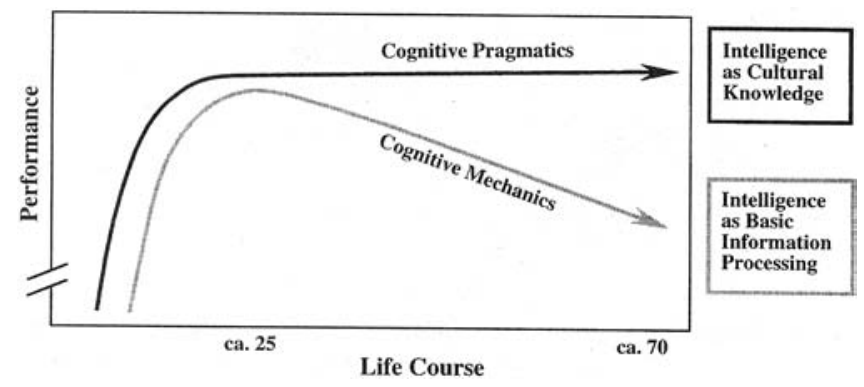

Note. Modified after P. B. Baltes, 1993; Horn, 1970. human brain as it was shaped by biocultural coevolution. At the operational level, we assume that the cognitive mechanics are indexed by the speed and accuracy of elementary processes of information processing: information input; visual and motor memory; and basic perceptual-cognitive processes such as discrimination, comparison, categorization, as well as their application in working memory. Because of the close connection of the fluid mechanics to the neurobiology of development, life span theory predicts some form of an inverted Ushape function across the life span, with decline beginning in young adulthood, if not earlier (P. B. Baltes \& Lindenberger, 1997; Horn \& Hofer, 1992).

The crystallized cognitive pragmatics can be understood as the culture-based "software" of the mind. They reflect the bodies of knowledge and information that cultures provide in the form of factual and procedural knowledge about the world, human affairs, socialization, and human agency (Cole, 1996; Klix, 1993). Examples of cognitive pragmatics are reading and writing skills; language; educational qualifications and professional skills; as well as knowledge about the self and about life skills that are relevant to the planning, conduct, and interpretation of life (P. B. Baltes, 1991; Brim, 1992; Smith, 1996; Staudinger \& Baltes, 1996b). The positive life span trajectory of the cognitive pragmatics, being primarily determined by cultural forces, can extend further into the life course than the mechanics. How far the trajectory extends is a function of two conditions. The first is the availability of cultural opportunities and their translation into programs of cognitive enhancement (P. B. Baltes, Lindenberger, \& Staudinger, 1995; Willis, 1990). The second is the limitation posed by the cognitive mechanics and their life span trajectory.

In general, the body of life span work on intellectual functioning is consistent with this dual-process model of intelligence. Thus, there are distinct differences in life span trajectories among cognitive tasks when tasks are grouped into more biology- or culture-based ones. Beginning in adulthood, for the cognitive mechanics, negative age gradients are obtained consistently for such component processes as working memory, speed of information processing, and inhibitory efficacy (Lindenberger \& Baltes, 1994; Salthouse, 1991). Age gradients for pragmatic tasks, on the other hand, such as for verbal performance tasks or for tasks of professional expertise, often evince maintenance into later phases of adulthood, and their trajectory is very dependent on life course experiential factors (P. B. Baltes, 1993; Blanchard-Fields \& Hess, 1995; Ericsson \& Smith, 1991; Salthouse, 1991). In addition, there is ample evidence about how the mechanics and pragmatics interact, for instance, how the cognitive pragmatics can be used to offset losses in the mechanics. Older adults, for example, who continue to be excellent typists, do so by reading further along in the text when typing to compensate for losses in reaction time (Salthouse, 1991).

In our own work over the past decades, my colleagues and I have attempted to study the development 
Figure 4

Adult Developmental Age Gradients for Measures of the Cognitive Mechanics (Lindenberger \& Baltes, 1995) and the Cognitive Pragmatics (Staudinger \& Baltes, 1996b)
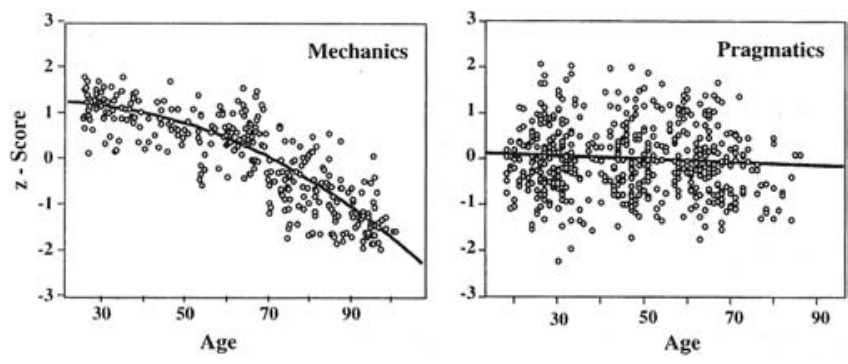

of the two basic categories of the mind with a primary focus on their maximal expression. For this purpose, we selected tasks that represented prototypes of the cognitive mechanics and pragmatics: working memory for the fluid mechanics and wisdom for the crystallized pragmatics (P. B. Baltes, 1993; P. B. Baltes, Lindenberger, \& Staudinger, 1995; Kliegl et al., 1989). For each of these prototypical tasks, we studied people of different ages under optimizing conditions to understand maximum performance potential and its age-associated changes. In addition, we demonstrated that a key component of the cognitive pragmatics is its social and collaborative nature such as expressed in the facilitative effect of interactive minds (Cole, 1996; Staudinger \& Baltes, 1996a). Figure 4 summarizes the main outcomes of our research on the dualprocess model of life span intelligence.

In the left part of Figure 4, data on psychometric intelligence tests are graphed, which reflect primarily the cognitive mechanics. These findings exhibit the typical age-loss trend beginning in early adult life (P. B. Baltes \& Lindenberger, 1997). Age losses, incidentally, become even more pronounced if, similar to stress tests in medicine, the focus is on maximum performance as studied by means of testing-the-limits methodology (P. B. Baltes \& Kliegl, 1992; Kliegl, Smith, \& Baltes, 1990). The right side of Figure 4 summarizes our evidence on age correlations that involve a prototype of the cognitive pragmatics, that is, wisdom, and the results are very different (P. B. Baltes \& Smith, 1990; P. B. Baltes \& Staudinger, 1993; Staudinger \& Baltes, 1996b). As predicted by the life span architecture outlined, the life span trajectory of wisdom-related performance extends further into the life span. In our data on wisdom, for instance, older adults performed as well as younger adults at least up to age 70. After that age, however, performance levels seemed to decline in wisdom tasks as well. In advanced old age, the life span biological architecture constrains more and more what culture and individuals can accomplish.

More recently, our work has been extended to include the study of predictive correlates of old-age intelli- gence to test another facet of the dual-process model of intellectual development, that is, the differential mechanisms and causal factors assumed to regulate life span development. One example is work on intelligence in the Berlin Aging Study (Mayer \& Baltes, 1996) in which 516 persons 70 to 103 years of age have been studied with an extensive battery of cognitive measures and a large set of culture- and biology-related indicators. From this evidence, I highlight four findings that demonstrate, as predicted by the life span architecture outlined, the powerful role of biological constraints in old age and the parallel decrease in efficacy of cultural factors (P. B. Baltes \& Lindenberger, 1997; Lindenberger \& Baltes, 1995, in press; Smith \& Baltes, 1996).

The first finding involves the increasing cascadelike effect of the generality of cognitive aging. As shown also in the longitudinal analyses of Schaie $(1988,1994$, 1996), with age, more and more of the cognitive abilities are involved in the loss pattern. Thus, when the age range of 70 to 100 years is reached, all cognitive dimensions exhibit losses (P. B. Baltes \& Lindenberger, 1997). There are large individual differences in initial level and onset of the aging losses, but the pattern seems universal. The second example concerns the age-associated increase in pathological aging. In particular, people at risk for Alzheimer's disease or categorized as demented demonstrate major losses (see also M. M. Baltes, Kühl, \& Sowarka, 1992).

The third exemplary finding concerns the role of culture-based life history in the regulation of cognitive aging. For instance, is old age kinder to the culturally advantaged? The basic biological architecture of the life span (see Figure 1) would suggest that the effect of cultural advantage may become progressively smaller as the individual ages, that is, the more the biological life span

\section{Figure 5 \\ Data From the Berlin Aging Study (Mayer \& Baltes, 1996)}

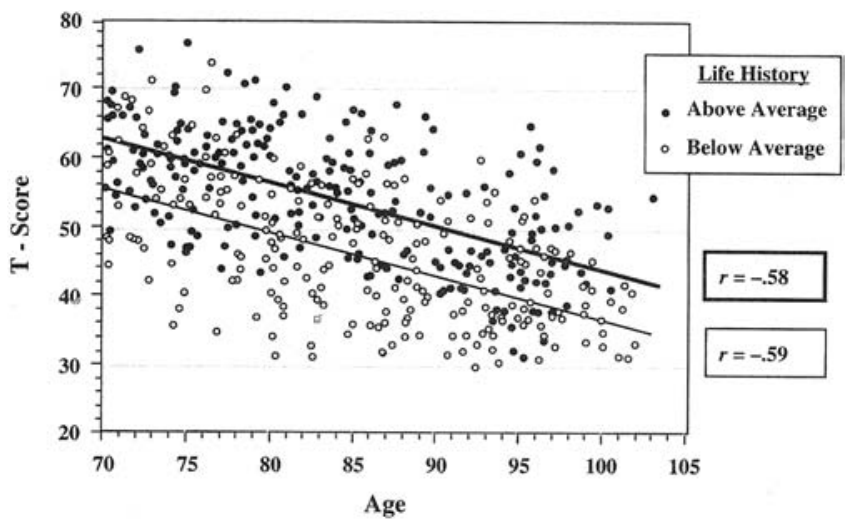

Note. Age gradients in intellectual functioning (based on 14 tests) are identical for subgroups reflecting above-average and below-average tife circumstances involving education, income, occupational status, and social prestige (Lindenberger \& Baltes, 1995). 
architecture is tested at its limits. In the Berlin Aging Study (Mayer \& Baltes, 1996), the outcome supports this prediction. As shown in Figure 5, the negative age gradient found for the aging of a general measure of intellectual performance applied to subgroups irrespective of their social and educational life histories and current life contexts. Whereas people from culturally and socially advantaged life histories entered old age at a higher average level of functioning, their subsequent negative age patterns were identical with those having experienced or experiencing less favorable life conditions. In other words, earlier advantages do not guard against decline.

The fourth exemplary finding is the powerful connection between physical functions and cognitive functioning that emerges in old age. In the Berlin Aging Study (Mayer \& Baltes, 1996), for instance, the telling result is the extremely strong association that my colleagues and I observed between basic sensorimotor functions (such as hearing, vision, and motor balance) and intellectual functioning. In old age, individual differences in these basic sensory and sensorimotor functions were found to correlate almost perfectly with age differences in the 14 tests of cognitive functioning studied (P. B. Baltes \& Lindenberger, 1997; Lindenberger \& Baltes, 1994).

Figure 6 illustrates the powerful association of sensory with intellectual functioning in old age by comparing the raw age gradient in an overall measure of general intelligence with the age gradient obtained after statistically controlling for sensory functioning. When simple measures of hearing, vision, and motor balance are used as covariates, the entire pattern of negative age differences in general intelligence disappears. Our preferred explanatory option is to invoke a common cause (thirdvariable hypothesis) for this powerful association between sensorimotor and cognitive functioning that emerges in old age. We suggest that age-related changes in neurophysiological brain functioning are assumed to affect at the same time sensory, sensorimotor, and cognitive functioning. This interpretation is also supported by evidence on brain atrophy (Lindenberger \& Baltes, 1996).

The pattern of these findings is fully consistent with the life span architecture outlined in Figure 1 and the dual-process model of intelligence. When it comes to the "hardware-like" cognitive mechanics and the speedy and accurate functioning of basic mechanisms of information processing, old age takes its toll, very much consistent with what is found in biological and physical indicators of functioning. Conversely, the life span trajectories for cognitive pragmatics, reflecting the enhancing contribution of cultural factors and the interactive mind's conditions of life (P. B. Baltes \& Staudinger, 1996), increase for a longer span of life. However, as old age is reached, the compensatory role of culture and culture-based behaviors and resources becomes less efficient. As a conse- quence, in advanced old age, the cognitive pragmatics such as wisdom decline as well.

\section{The Fourth Age: The Most Radical Form of Incompleteness}

In conclusion, I concentrate on advanced old age that, following the tradition described in Laslett (1991), I propose to call the fourth age. The nature of the fourth age (from about 80 years onward) is, in my opinion, the major new frontier for future research and theory in life span development as well as for efforts in human development policy. Two arguments lay the foundation for the following observations: (a) the fundamental incompleteness of the biological and cultural architecture of the life span as outlined above and (b) recent findings on advanced old age as obtained, for instance, by the Berlin Aging Study (P. B. Baltes, Mayer, Helmchen, \& Steinhagen-Thiessen, 1996; Mayer \& Baltes, 1996; Smith \&

Figure 6

Data From the Berlin Aging Study (Mayer \& Baltes, 1996)
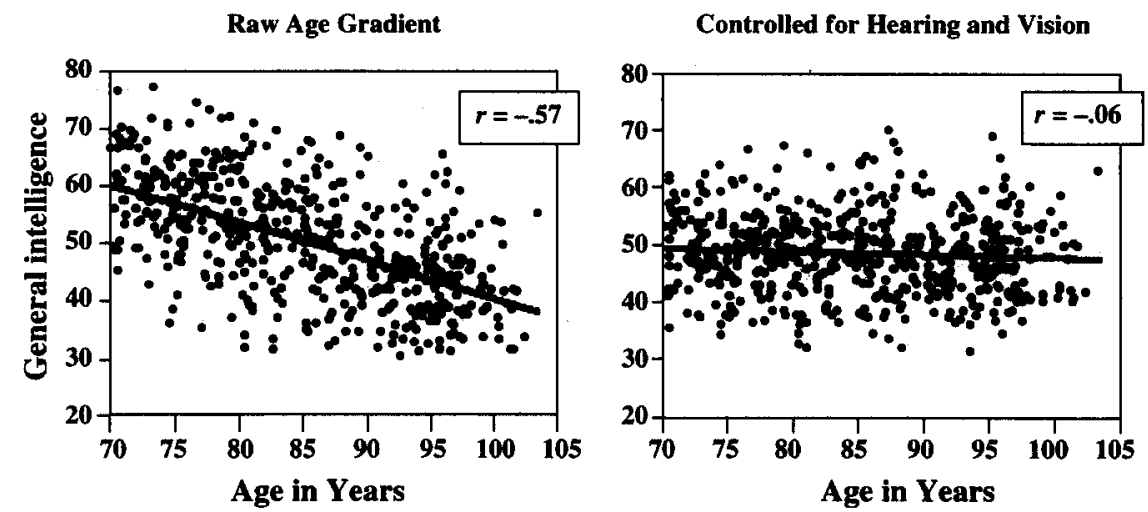

Note. Measures of visual acuity and auditory threshold sensitivity in advanced old age predict the whole of age differences (from 70 to 100 ) in intellectual functioning (modified after P. B. Baltes \& Lindenberger, 1997; Lindenberger \& Baltes, 1994). The same pattern applies to a measure of sensorimotor balance. 
Baltes, 1996). These findings differ in some dramatic ways from research on young-old age.

During the last decades, we have witnessed a growing success story regarding young-old age (Birren \& Schaie, 1996). Because of medical, technical, social, economic, and educational advances, the overall gestalt of life for 60- and 70-year-olds has made major strides in indicators of health and psychological functioning. For this period of the third age, cultural and social forces in industrialized countries have been able to offset, for the most part and for more and more individuals, the weaknesses inherent in the biological life span architecture.

What about advanced old age, however? What is the evidence that the same trend will continue as people increase the number of remaining years in old age as well? Thus far, the increase in life expectancy was primarily based on the reduction of mortality in younger ages. Recent demographic research by Manton, Vaupel, and others (Manton \& Vaupel, 1995; Vaupel \& Jeune, 1995), however, has shown that during the last decades of this century, the increase in average life expectancy was not only due to the fact that more persons reached higher ages but also to the fact that older persons live longer. Eighty-year-olds, for instance, over the last three decades in northern Europe have increased their remaining lifetime from about four years to seven years.

The basic architecture of the life span displayed in Figure 1 suggests that these added years will not harbor the same potential as earlier gains in life expectancy. Not surprisingly, therefore, we are witnessing a new line of inquiry in aging research. More and more of the current gerontological work concentrates on such questions as the plasticity and quality of life in old age, how to define it, and how to measure it and to assess the degree to which it shows historical cohort- and age-related changes.

A key question in this research is whether potential and quality of life are different in advanced old age than in young-old age. A recent analysis of Americans, for instance, by Crimmins, Hayward, and Saito (1996) suggested that the percentage of dysfunctional-inactive years of the remaining lifetime is $20 \%$ for 70 -year-old women,

Table 2

Quality of Life in Old Age: Dysfunctional-Inactive Proportions of Remaining Years

\begin{tabular}{lll}
\hline & \multicolumn{2}{c}{ Dysfunctional-inactive percentage } \\
\cline { 2 - 3 } Age & \multicolumn{1}{c}{ Women } & Men \\
\hline 70 & $20 \%$ of 14 years & $14 \%$ of 10 years \\
80 & $35 \%$ of 8 years & $27 \%$ of 6 years \\
90 & $60 \%$ of 5 years & $55 \%$ of 3 years \\
\hline
\end{tabular}

Note. Data are for U.S. residents. Aggregated from information contained in Crimmins et al. (1996). Dysfunctional-inaclive life $=$ independent living not possible (basic everyday skills).
Figure 7

Data From the Berlin Aging Study (Mayer \& Baltes, 1996)

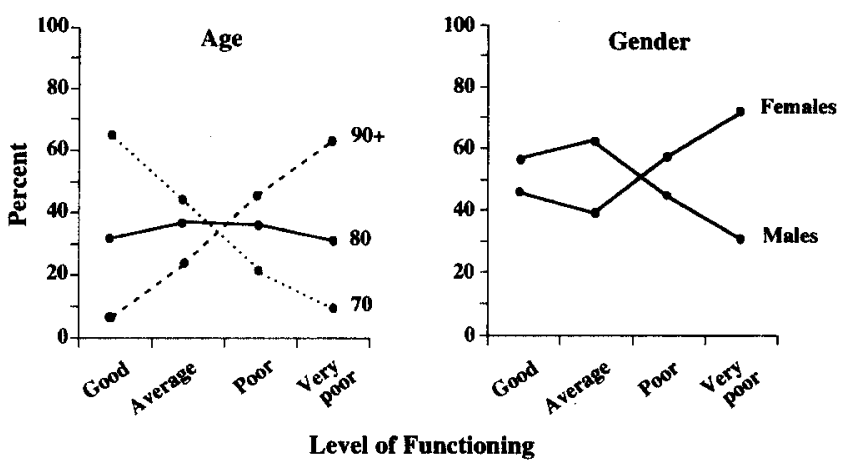

Note. Research participants were distributed (by age and gender) into four groups differing in functional status. Groups were formed by considering a total of 23 physical, mental, and social indicators (Mayer \& Baltes, 1996; Smith \& Baltes, 1996].

whereas for 90 -year-olds, close to $60 \%$ of the remaining years represent dysfunctional-inactive time (see Table 2). In this instance, dysfunctionality or inactivity was measured by indicators of everyday competence and independent living. These are dramatic age-related losses in functional status as people move from the third to the fourth age. The oldest old are not simply individuals who contimue to stay alive because their functional status remains at the same level as that of the younger old.

The Berlin Aging Study (Mayer \& Baltes, 1996), because of its wide age range and broad interdisciplinary assessment, offers a new window on this question of potential and quality of life in advanced old age. As shown in Figure 7, in one analysis (Mayer \& Baltes, 1996; Smith \& Baltes, in press) we used a total of 23 indicators of physical, psychiatric, psychological, social, and economic functioning. Using cluster analysis, we then explored age differences from 70 to 100 years. Note here that, because of the stratified sample used in the Berlin Aging Study, these comparisons involved equal numbers of persons in each age and gender group.

In Figure 7, the participants in the Berlin Aging Study $(N=516)$ were subdivided into four subgroups that descended in the quality of functional status and subjective well-being from good to average to poor and very poor. The outcome is clear. As shown in the left part of the figure, the oldest old appear much more frequently in undesirable clusters than the younger old. In the functionally best group (good), for instance, we found about 10 times more 70 -year-olds than 90 -year-olds. The reverse was true for the very poor group. In this extreme group of dysfunctionality, 90-year-olds were much more frequent than 70-year-olds. These are dramatic age differences in risk ratios. Although further analyses, including longitudinal, cohort-sequential, and interventive ones, need to be conducted to substantiate this pattern of re- 
sults, the central outcome is unlikely to change. The oldest old are at a much higher risk for dysfunctionality than the young-old.

The right part of Figure 7 shows that there are also major gender differences in risks for old-age dysfunctionality (Smith \& Baltes, 1996). The relative risk is significantly greater for women than men, and it becomes larger the higher the age. The female gender risk factor in the most dysfunctional group is about two. Thus, although women live longer than men, their functional status is less desirable, and this disadvantage increases with age. Although this is speculative, this gender difference may have a strong evolutionary basis. For men, because of their longer fertility and the role of dominance in reproductive fitness, selection may have favored vital biological functioning. For women and their role in nurturance, selection may have favored length of life over physical strength-related vitality of life.

This pattern of a major increase in risk for the fourth age is not only noticeable when physical variables are considered but also when the sole focus is on psychological measures such as intelligence, the self, personality, and social behavior (Smith \& Baltes, 1996). On the level of individual psychological variables, and with the exception of intelligence, the negative age effects were relatively small. However, all significant age-difference effects were in the same direction, that is, toward more dysfunctionality in advanced old age. Thus, when the effects were aggregated into multivariate profiles, the negativity of the psychological aging patterns became more and more dramatic. Psychologically speaking, advanced old age presented itself more and more like a situation with high demand and stress characteristics. Advanced old age, the fourth age, is a kind of testing-thelimits situation for psychological resilience.

The relatively pessimistic picture for advanced old age is perhaps most conspicuous when the most prevalent old-age mental illness is considered, senile dementia of the Alzheimer's type. In the Berlin Aging Study (Helmchen et al., 1996; Mayer \& Baltes, 1996) - and these findings are consistent with research by others - the prevalence of all diagnoses (mild, moderate, severe) of Alzheimer's dementia increased from about $2-3 \%$ in 70 -year-olds, $10-$ $15 \%$ in 80 - to 90 -year-olds, to about $50 \%$ in 90 -year-olds. Alzheimer's disease is the condition that older persons fear most. Its manifestation is often outside the dignity that humans aspire for themselves. Currently, there is no effective therapy available. Thus, if, as demographic analyses suggest (Manton \& Vaupel, 1995; Vaupel \& Jeune, 1995), the recent trend of an increase in remaining lifetime for the oldest old of the population continues, it is likely that the incidences of Alzheimer's dementia will increase as well. The major exception to this prediction would be as yet uncharted medical advances in the preventive and remedial treatment of this disease.

\section{Summary and Outlook}

This article deals with the search for the most general frame of human development across the life span. The purpose is twofold: first, to stimulate developmentalists to embrace in their work the consideration of what I call the incomplete and changing architecture of the life span and second, to alert psychologists to the special forces and challenges of a fourth age.

Proceeding across several levels of analyses, I opened with general evolutionary considerations on the basic architecture of the life course. The proposed frame of constraints, which I judge to be fairly robust and therefore deserving of being called an architecture, contains three elements: First, evolution neglected old age, and, therefore, biological potential wanes with age. Second, for development to extend into progressively later portions of the life span, more and more culture is required. Third, because of the age-linked weakening of biological potential, the efficiency of culture decreases with age.

Informed by this biological and social architectural frame, I proceeded to identify a life span script in the relative allocation of resources into the three major functions of ontogenetic development: growth, maintenance (resilience), and the regulation or management of loss. Subsequently, I described a general metatheory of adaptive (successful) human development, SOC, which I concluded to be consistent with the life span architecture outlined and to represent a general model of effective adaptation or mastery. In a final step, I applied these general considerations to specific instantiations of developmental research and theory: the life span developmental study of intelligence and the nature of advanced old age.

In my view, the most pressing challenge for human developmentalists of the next century is to search for the conditions required to complete the biological and cultural architecture of the life span so that the optimization of development (in the sense of achieving a positive balance between gains and losses; P. B. Baltes, 1987) extends further and further into the later periods of the life span. Because of the robustness of the incomplete architecture of the life course, however, it is likely that extending positive human development into progressively higher ages will be increasingly more difficult. To this end, psychologists' collaboration with other disciplines engaged in remedying the incomplete architecture of the life span, such as biology, medicine, the social sciences, as well as practical anthropology, seems paramount.

A concluding observation is as follows: Although I do suggest that the optimization of human development is increasingly difficult as it is extended into advanced old age, I do not want to leave the impression that completion, in the sense of achieving a positive balance of gains and losses for all ages of life, is not possible in principle. Neither the biological matrix nor the current state of the cultural world ought to be viewed as a fixed representation of "the" nature of human aging. States of deficit and limitations, such as the fourth age, are powerful catalysts for scientific and cultural innovation. Furthermore, despite age losses in plasticity, there is latent potential for enhancement of functioning in old age 
as well (M. M. Baltes \& Carstensen, 1996; P. B. Baltes, 1991, 1993).

In this spirit, we need to keep in mind that the future is not something we simply enter; the future is also something we help create. Of particular importance is the question of whether humankind will opt for remedying the basic incompleteness of the biological life span architecture through various techniques of genetic interventions aimed at the optimization of individual functioning. Despite the serious ethical issues, dilemmas, and possible misuses involved, my judgment is that it will be difficult to resist this genetic-intervention option. Why? The degree of biological incompleteness in advanced old age is a radical one. Thus, cultural and psychological factors alone would seem to be insufficient to generate for most individuals the kind of functional status in advanced old age in which gains outnumber losses and where human dignity prevails.

\section{REFERENCES}

Bäckman, L., \& Dixon, R. A. (1992). Psychological compensation: A theoretical framework. Psychological Bulletin, 112, 1-25.

Baltes, M. M. (1996). The many faces of dependency in old age. New York: Cambridge University Press.

Baltes, M. M., \& Carstensen, L. L. (1996). The process of successful ageing. Ageing and Society, 16, 397-422.

Baltes, M. M., Kühl, K.-P., \& Sowarka, D. (1992). Testing for limits of cognitive reserve capacity: A promising strategy for early diagnosis of dementia? Journal of Gerontology: Psychological Sciences, 47, P165-P167.

Baltes, M. M., \& Silverberg, S. B. (1994). The dynamics between dependency and autonomy: Illustrations across the life span. In D. L. Featherman, R. M. Lerner, \& M. Perlmutter (Eds.), Life span development and behavior (Vol. 12, pp. 41-90). Hillsdale, NJ: Erlbaum.

Baltes, P. B. (1979). Life-span developmental psychology: Some converging observations on history and theory. In P. B. Baltes \& O. G. Brim, Jr. (Eds.), Life-span development and behavior (Vol. 2, pp. 255-279). New York: Academic Press.

Baltes, P. B. (1987). Theoretical propositions of life-span developmental pyschology: On the dynamics between growth and decline. Developmental Psychology, 23, 611-696.

Baltes, P. B. (1991). The many faces of human aging: Toward a psychological culture of old age. Psychological Medicine, 21, 837-854.

Baltes, P. B. (1993). The aging mind: Potential and limits. Gerontologist, 33, 580-594.

Baltes, P. B. (1994, August). On the overall landscape of human development. Invited address at the 102nd Annual Convention of the American Psychological Association, Los Angeles.

Baltes, P. B., \& Baltes, M. M. (1980). Plasticity and variability in psychological aging: Methodological and theoretical issues. In G. E. Gurski (Ed.), Determining the effects of aging on the central nervous system (pp. 41-66). Berlin, Germany: Schering.

Baltes, P. B., \& Baltes, M. M. (1990). Psychological perspectives on successful aging: The model of selective optimization with compensation. In P. B. Baltes \& M. M. Baltes (Eds.), Successful aging: Perspectives from the behavioral sciences (pp. 1-34). New York: Cambridge University Press.

Baltes, P. B., Baltes, M. M., Freund, A. M., \& Lang, F. R. (1995). Measurement of selective optimization with compensation by questionnaire. Berlin, Germany: Max Planck Institute for Human Development and Education.

Baltes, P. B., Dittmann-Kohli, F., \& Dixon, R. A. (1984). New perspectives on the development of intelligence in adulthood: Toward a dualprocess conception and a model of selective optimization with compensation. In P. B. Baltes \& O. G. Brim, Jr. (Eds.), Life-span development and behavior (Vol. 6, pp. 33-76). New York: Academic Press.
Baltes, P. B., \& Graf, P. (1996). Psychological aspects of aging: Facts and frontiers. In D. Magnusson (Ed.), The lifespan development of individuals: Behavioural, neurobiological and psychosocial perspectives (pp. 427-460). Cambridge, England: Cambridge University Press.

Baltes, P. B., \& Kliegl, R. (1992). Further testing of limits of cognitive plasticity: Negative age differences in a mnemonic skill are robust. Developmental Psychology, 28, 121-125.

Baltes, P. B., \& Lindenberger, U. (1997). Emergence of a powerful connection between sensory and cognitive functions across the adult life span: A new window at the study of cognitive aging? Psychology and Aging, 12, 12-21.

Baltes, P. B., Lindenberger, U., \& Staudinger, U. M. (1995). Die zwei Gesichter der Intelligenz im Alter [The two faces of intelligence in old age]. Spektrum der Wissenschaft, 10, 52-61.

Baltes, P. B., Lindenberger, U., \& Staudinger, U. M. (in press). Lifespan theory in developmental psychology. In R. M. Lerner (Ed.), Handbook of child psychology: Vol. 1. Theoretical models of human development (5th ed.). New York: Wiley.

Baltes, P. B., Mayer, K. U., Helmchen, H., \& Steinhagen-Thiessen, E. (1996). Die Berliner Altersstudie (BASE): Überblick und Einführung [The Berlin Aging Study: Overview and introduction]. In K. U. Mayer \& P. B. Baltes (Eds.), Die Berliner Alterstudie (pp. 21-54). Berlin, Germany: Akademie Verlag.

Baltes, P. B., \& Schaie, K. W. (1976). On the plasticity of intelligence in adulthood and old age: Where Horn and Donaldson fail. American Psychologist, 31, 720-725.

Baltes, P. B., \& Smith, J. (1990). The psychology of wisdom and its ontogenesis. In R. J. Sternberg (Ed.), Wisdom: Its nature, origins, and development (pp. 87-120). New York: Cambridge University Press.

Baltes, P. B., \& Staudinger, U. M. (1993). The search for a psychology of wisdom. Current Directions in Psychological Science, 2, 75-80.

Baltes, P. B., \& Staudinger, U. M. (Eds.). (1996). Interactive minds: Life-span perspectives on the social foundation of cognition. New York: Cambridge University Press.

Barkow, J. H., Cosmides, L., \& Tooby, J. (Eds.). (1992). The adapted mind: Evolutionary psychology and the generation of culture. New York: Oxford University Press.

Birren, J. E., \& Schaie, K. W. (1996). Handbook of the psychology of aging (3rd ed.). San Diego, CA: Academic Press.

Blanchard-Fields, F., \& Hess, T. (Eds.). (1995). Perspectives on cognitive change in adulthood. New York: McGraw-Hill.

Boesch, E. E. (1991). Symbolic action theory and cultural psychology. Heidelberg, Germany: Springer.

Brandtstädter, J. (1984). Personal and social control over development: Some implications of an action perspective in life-span developmental psychology. In P. B. Baltes \& O. G. Brim, Jr. (Eds.), Lifespan development and behavior (Vol. 6, pp. 1-32). New York: Academic Press.

Brandtstädter, J. (in press). Action theory in developmental psychology. In R. M. Lerner (Ed.), Handbook of child psychology: Vol. 1. Theoretical models of human development (5th ed.). New York: Wiley.

Brandtstädter, J., \& Wentura, D. (1995). Adjustment to shifting possibility frontiers in later life: Complementary adaptive modes. In R. A. Dixon \& L. Bäckman (Eds.), Psychological compensation: Managing losses and promoting gains (pp. 83-106). Hillsdale, NJ: Erlbaum.

Brim, O. G., Jr. (1992). Ambition: How we manage success and failure throughout our lives. New York: Basic Books.

Burghardt, G. M. (1984). On the origins of play. In P. K. Smith (Ed.), Play in animals and humans (pp. 1-45). London: Basil Blackwell.

Cantor, N., \& Fleeson, W. (1994). Social intelligence and intelligent goal pursuit: A cognitive slice of motivation. In W. D. Spaulding (Ed.), Nebraska Symposium on Motivation: Vol. 41. Integrative views of motivation, cognition, and emotion (pp. 125-179). Lincoln: University of Nebraska Press.

Carstensen, L. L., Hanson, K. A., \& Freund, A. (1995). Selection and compensation in adulthood. In R. Dixon \& L. Bäckman (Eds.), Compensating for psychological deficits and declines: Managing losses and promoting gains (pp. 107-126). Hillsdale, NJ: Erlbaum. 
Cattell, K. B. (1971). Abilities: Their structure, growth, and action. Boston: Houghton Mifflin.

Cole, M. (1996). Interacting minds in a lifespan perspective: A cultural/ historical approach to culture and cognitive development. In P. B. Baltes \& U. M. Staudinger (Eds.), Interactive minds: Life-span perspectives on the social foundation of cognition (pp. 59-87). New York: Cambridge University Press.

Craik, F. I. M., \& Salthouse, T. A. (Eds.). (1992). The handbook of aging and cognition. Hillsdale, NJ: Erlbaum.

Crimmins, E. M., Hayward, M. D., \& Saito, Y. (1996). Differentials in active life expectancy in the older population of the United States. Journal of Gerontology: Social Sciences, 51B, S111-S120.

D'Andrade, R. (1995). The development of cognitive anthropology. Cambridge, England: Cambridge University Press.

Dittmann-Kohli, F. (1995). Das persönliche Sinnsystem: Ein Vergleich zwischen frühem und spätem Erwachsenenalter [Personal meaning systems: Age differences in adult development and aging]. Göttingen, Germany: Hogrefe.

Dixon, R. A., \& Bäckman, L. (Eds.). (1995). Compensating for psychological deficits and declines: Managing losses and promoting gains. Hillsdale, NJ: Erlbaum.

Durham, W. H. (1991). Coevolution: Genes, culture and human diversity. Stanford, CA: Stanford University Press.

Edelman, G. M. (1987). Neural Darwinism: The theory of neuronal group selection. New York: Basic Books.

Edelman, G. M., \& Tononi, G. (1996). Selection and development: The brain as a complex system. In D. Magnusson (Ed.), The life-span development of individuals: Behavioral, neurobiological and psychosocial perspectives (pp. 179-204). Cambridge, England: Cambridge University Press.

Elder, G. H. (in press). Life-course theory. In R. M. Lerner (Ed.), Handbook of child psychology: Vol. 1. Theoretical models of human development (5th ed.). New York: Wiley.

Ericsson, K. A., \& Smith, J. (Eds.). (1991). Towards a general theory of expertise: Prospects and limits. New York: Cambridge University Press.

Featherman, D. L. (1983). The life-span perspective in social science research. In P. B. Baltes \& O. G. Brim, Jr. (Eds.), Life-span development and behavior (Vol. 5, pp. 1-59). New York: Academic Press.

Finch, C. E. (1990). Longevity, senescence, and the genome. Chicago: University of Chicago Press.

Finch, C. E. (1996). Biological bases for plasticity during aging of individual life histories. In D. Magnusson (Ed.), The life-span development of individuals: Behavioral, neurobiological and psychosocial perspective (pp. 488-511). Cambridge, England: Cambridge University Press.

Finch, C. E., \& Rose, M. R. (1995). Hormones and the physiological architecture of life history evolution. The Quarterly Review of Biology, 70, 1-52.

Freund, A. M., \& Baltes, P. B. (1996). Selective optimization with compensation as a strategy of life-management: Prediction of subjective indicators of successful aging. Unpublished manuscript, Max Planck Institute for Human Development and Education, Berlin.

Hebb, D. O. (1949). The organization of behavior. New York: Wiley.

Heckhausen, J., Dixon, R. A., \& Baltes, P. B. (1989). Gains and losses in development throughout adulthood as perceived by different adult age groups. Developmental Psychology, 25, 109-121.

Heckhausen, J., \& Schulz, R. (1995). A life-span theory of control. Psychological Review, 102, 284-304.

Helmchen, H., Baltes, M. M., Geiselmann, B., Kanowski, S., Linden, M., Reischies, F. M., Wagner, M., \& Wilms, H.-U. (1996). Psychische Erkrankungen im Alter [Psychiatric illnesses in old age]. In K. U. Mayer \& P. B. Baltes (Eds.), Die Berliner Altersstudie (pp. 185220). Berlin, Germany: Akademie Verlag.

Hetherington, E. M., \& Baltes, P. B. (1988). Child psychology and lifespan development. In E. M. Hetherington, R. M. Lerner, \& M. Perlmutter (Eds.), Child development in life-span perspective (pp. 119). Hillsdale, NJ: Erlbaum.

Hobfoll, S. E. (1989). Conservation of resources: A new attempt at conceptualizing stress. American Psychologist, 44, 513-524.

Horn, J. L. (1970). Organization of data on life-span development of human abilities. In L. R. Goulet \& P. B. Baltes (Eds.), Life-span developmental psychology: Research and theory (pp. 423-466). New York: Academic Press.

Horn, J. L., \& Hofer, S. M. (1992). Major abilities and development in the adult period. In R. J. Sternberg \& C. A. Berg (Eds.), Intellectual development (pp. 44-99). New York: Cambridge University Press.

Kahneman, D., \& Tversky, A. (1984). Choices, values, and frames. American Psychologist, 39, 341-350.

Kliegl, R., Mayr, U., \& Krampe, R. T. (1994). Time-accuracy functions for determining process and person differences: An application to cognitive aging. Cognitive Psychology, 26, 134-164.

Kliegl, R., Smith, J., \& Baltes, P. B. (1989). Testing-the-limits and the study of age differences in cognitive plasticity of a mnemonic skill. Developmental Psychology, 26, 894-904.

Kliegl, R., Smith, J., \& Baltes, P. B. (1990). On the locus and process of magnification of age differences during mnemonic training. Developmental Psychology, 26, 894-904.

Klix, F. (1993). Erwachendes Denken: Geistige Leistungen aus evolutionspsychologischer Sicht [The evolution of thinking: The mind from an evolutionary-psychological perspective]. Heidelberg, Germany: Spektrum Akademischer Verlag.

Labouvie-Vief, G. (1982). Dynamic development and mature autonomy: A theoretical prologue. Human Development, 25, 161-191.

Laslett, P. (1991). A fresh map of life: The emergence of the Third Age. Cambridge, MA: Harvard University Press.

Lerner, R. M. (1984). On the nature of human plasticity. New York: Cambridge University Press.

Lerner, R. M. (1986). Concepts and theories of human development (2nd ed.). New York: Random House.

Levelt, W. J. M. (1989). Speaking: From intention to articulation. Cambridge, MA: MIT Press.

Lindenberger, U., \& Baltes, P. B. (1994). Sensory functioning and intelligence in old age: A strong connection. Psychology and Aging, 9, 339-355.

Lindenberger, U., \& Baltes, P. B. (1995). Kognitive Leistungsfähigkeit im hohen Alter: Erste Ergebnisse aus der Berliner Altersstudie [Cognitive capacity in old age: First results from the Berlin Aging Study]. Zeitschrift für Psychologie, 203, 283-317.

Lindenberger, U., \& Baltes, P. B. (in press). Intellectual functioning in old and very old age: First results from the Berlin Aging Study. Psychology and Aging.

Magnusson, D. (Ed.). (1996). The life-span development of individuals: Behavioural, neurobiological, and psychosocial perspectives. Cambridge, England: Cambridge University Press.

Manton, K. G., \& Vaupel, J. W. (1995). Survival after the age of 80 in the United States, Sweden, France, England and Japan. New England Journal of Medicine, 333, 1232-1235.

Marsiske, M., Lang, F. R., Baltes, M. M., \& Baltes, P. B. (1995). Selective optimization with compensation: Life-span perspectives on successful human development. In R. A. Dixon \& L. Bäckman (Eds.), Compensation for psychological defects and declines: Managing losses and promoting gains (pp. 35-79). Hillsdale, NJ: Erlbaum.

Martin, G. M., Austad, S. N., \& Johnson, T. E. (1996). Genetic analysis of ageing: Role of oxidative damage and environmental stresses. Nature Genetics, 13, 25-34.

Mayer, K. U., \& Baltes, P. B. (Eds.). (1996). Die Berliner Altersstudie [The Berlin Aging Study]. Berlin, Germany: Akademie Verlag.

Nesselroade, J. R., \& Jones, C. J. (1991). Multi-model selection effects in the study of adult development: A perspective on multivariate, replicated, single-subject, repeated measures designs. Experimental Aging Research, 17, 21-27.

Osiewacz, H. D. (1995). Molekulare Mechanismen biologischen Alterns [Molecular mechanisms of biological aging]. Biologie in unserer Zeit, 25, 336-344.

Rose, M. R. (1991). The evolutionary biology of aging. Oxford, England: Oxford University Press.

Rosenmayr, L. (1990). Die Kraffe des Alters [The powers of old age]. Wien, Germany: Edition Atelier.

Salthouse, T. A. (1991). Theoretical perspectives on cognitive aging. Hillsdale, NJ: Erlbaum.

Schaie, K. W. (1988). The hazards of cognitive aging. Gerontologist, $29,484-493$. 
Schaie, K. W. (1994). The course of adult intellectual development. American Psychologist, 49, 304-313.

Schaie, K. W. (1996). Adult intellectual development: The Seattle Longitudinal Study. New York: Cambridge University Press.

Schulz, R., \& Heckhausen, J. (1996). A life-span model of successful aging. American Psychologist, 51, 702-714.

Shweder, R. A. (1991). Thinking through cultures. Cambridge, MA: Harvard University Press.

Siegler, R. S. (1994). Cognitive variability: A key to understanding cognitive development. Current Directions in Psychological Science, $3,1-5$.

Smith, J. (1996). Planning about life: Toward a social-interactive perspective. In P. B. Baltes \& U. M. Staudinger (Eds.), Interactive minds: Life-span perspectives on the social foundation of cognition (pp. 242-275). Cambridge, England: Cambridge University Press.

Smith, J., \& Baltes, P. B. (1996). Altern aus psychologischer Perspektive: Trends und Profile im hohen Alter [Psychological aging: Trends and profiles in very old age]. In K. U. Mayer \& P. B. Baltes (Eds.), Die Berliner Altersstudie (pp. 221-250). Berlin, Germany: Akademie Verlag.

Smith, J., \& Baltes, P. B. (in press). Profiles of psychological functioning in the old and oldest-old. Psychology and Aging.

Staudinger, U. M., \& Baltes, P. B. (1996a). Interactive minds: A facilitative setting for wisdom-related performance? Journal of Personality and Social Psychology, 71, 746-762.

Staudinger, U. M., \& Baltes, P. B. (1996b). Weisheit als Gegenstand psychologischer Forschung [Wisdom as a topic of psychological research]. Psychologische Rundschau, 47, 57-77.
Staudinger, U. M., Marsiske, M., \& Baltes, P. B. (1995). Resilience and reserve capacity in later adulthood: Potentials and limits of development across the life span. In D. Cicchetti \& D. Cohen (Eds.), Developmental psychopathology: Vol. 2. Risk, disorder, and adaptation (pp $801-847)$. New York: Wiley.

Takahashi, K. (1990). Affective relationships and their lifelong development. In P. B. Baltes, D. L. Featherman, \& R. M. Lerner (Eds.), Life span development and behavior (Vol. 10, pp. 1-27). Hillsdale, NJ: Erlbaum.

Tetens, J. N. (1777). Philosophische Versuche über die menschliche Natur und ihre Entwicklung [Philosophical essays on human nature and its development]. Leipzig; Germany: Weidmanns Erben und Reich.

Thelen, E., \& Smith, L. B. (1994). A dynamic systems approach to the development of cognition and action. Cambridge, MA: MIT Press.

Uttal, D. H., \& Perlmutter, M. (1989). Toward a broader conceptualization of development: The role of gains and losses across the life span. Developmental Review, 9, 101-132.

Vaupel, J. W., \& Jeune, B. (1995). Exceptional longevity: From prehistory to the present. Odense, Denmark: Odense University Press.

Waddington, C. H. (1975). The evolution of an evolutionist. Edinburgh, Scotland: Edinburgh University Press.

Willis, S. L. (1990). Contributions of cognitive training research to understanding late-life potential. In M. Perlmutter (Ed.), Late-life potential (pp. 25-42). Washington, DC: The Gerontological Society of America.

Yates, E., \& Benton, L. A. (1995). Biological senescence: Loss of integration and resilience. Canadian Journal on Aging, 14, 106-120. 